\title{
DECISION SUPPORT FOR AGRICULTURAL WATER MANAGEMENT
}

\author{
Y. PANAGOPOULOS \\ C. MAKROPOULOS \\ M. MIMIKOU
}

\author{
Laboratory of Hydrology and Water Resources Management \\ Department of Water Resources and Environmental Engineering \\ School of Civil Engineering, National Technical University of Athens (NTUA) \\ 5, Iroon Politechniou street, 15780, Zografou, Athens, Greece
}

Received: 05/12/11

*to whom all correspondence should be addressed:

Accepted: 27/07/12

e-mail: ypanag@chi.civil.ntua.gr

\begin{abstract}
Irrigation water use is the major pressure limiting the availability of fresh water resources in the Mediterranean. Efficient irrigation scheduling programs (IRSPS) are able to reduce water consumption; however, their selection and placement in large agricultural landscapes depend on location specific characteristics and economic indicators. Towards this end, a novel and efficient Decision Support Tool (DST) is developed in MATLAB-programming, able to assess the effectiveness of different IRSPs in reducing total agricultural water use at the catchment scale along with their impact on crop yields. The DST integrates a look-up table with data on irrigation water amounts and crop yields at different locations within a catchment, populated by a hydrological and crop growth estimator: the process-based SWAT model, into a multi-objective Genetic Algorithm, which serves as the optimization engine for the allocation of measures across the agricultural land. The optimization scheme leads rapidly to the optimal trade-off frontier between the conflicting objectives providing spatial allocations of IRSPS. The tool was implemented in the Ali Efenti catchment demonstrating optimal solutions that could save more than $10 \%$ of water by reducing cotton yields less than $5 \%$ from the baseline. The study highlights the potential of the tool to assist in the development of cost-effective water saving plans at the catchment level in order to reduce the risk of desertification in intensively cultivated areas.
\end{abstract}

KEYWORDS: Irrigation practices, Decision support, Genetic algorithm, MATLAB, Multi-objective optimization, SWAT, Trade-off.

\section{INTRODUCTION}

In the Mediterranean region, agriculture is an essential driving force in the management of water use having significant impacts on water quantity and quality. Especially in Greece, agriculture is by far the largest consumer of freshwater resources accounting for nearly $90 \%$ of the total abstractions (Wriedt et al., 2009). In order to retain water quantity (and quality) of European water bodies at desirable levels, the coordination of cost-effective measures at the catchment scale form part of the interventions that should be included in the integrated River Basin Management Plans (RBMPs), required by the Water Framework Directive (WFD, Directive 2000/60/EC, 2000). Most of the modeling methodologies, developed to assist in meeting such objectives, seek to accurately calculate crop irrigation requirements, following the standard modeling approach of the FAO guideline (Allen et al., 1998). These requirements are calculated as the difference between the cropspecific potential evapotranspiration and the effective precipitation, while a soil water balance model accounts for soil moisture and its impact on actual crop. It can be thus concluded that irrigation requirements vary greatly across the landscape according to the local meteorological, landuse and soil characteristics, meaning that in order to save water without significantly reducing production levels there is a need to identify optimal locations for implementation of appropriate irrigation scheduling programs (IRSPS). 
To address this multi-objective problem the following elements are required from a Decision Support methodological framework: (a) a process-based model, which can represent the effect of irrigation management at the catchment scale on the parameters of interest (irrigation applied and crop production levels), and (b) an efficient multi-objective optimization algorithm, i.e. evolutionary algorithms or Genetic algorithms (GAs) (Schwefel, 2000; Makropoulos and Butler, 2005; Nicklow et al., 2010). Multi-objective evolutionary algorithms are capable of treating several objectives separately and develop a global Pareto-optimal front, subsequently used by decision makers to explore trade-offs between (pareto) optimal solutions, in a transparent way that can potentially take into account specific local circumstance and priorities (Tan et al., 2002).

Regarding the first point, the Soil and Water Assessment Tool (SWAT) model (Arnold et al., 1998) is probably the most widely known process-based distributed tool for simulating management in agricultural catchments and has been extensively applied alone or combined with other tools (Gassman et al., 2007). For example, there are numerous studies that have combined SWAT with a GA to optimize the selection and placement of agricultural practices across catchments (e.g. Arabi et al., 2006; Gitau et al., 2006; Jha et al., 2009; Rabotyagov et al., 2010); however, in those examples the model was proven inefficient. A notable example is the recent study of Panagopoulos et al. (2012), who have substituted the dynamic linkage between SWAT and the optimization algorithm by a database that serves, in this case, as the real-time pollutant load estimator and cost data provider; this led to a significant acceleration of the process. This approach was followed in this paper, which additionally innovates on the incorporation of irrigation practices into the tool. Although many recent studies have used SWAT to test measures aiming to improve agricultural water use efficiency and/or crop productivity (e.g. Luo et al., 2008;, Feng and Baoguo, 2010; Srivastava et al., 2010), the model has not yet been used within such an optimization scheme with the purpose to optimize the efficiency of spatial allocations of various IRSPs in meeting conflicting environmental and crop productivity objectives.

In this paper, we demonstrate the development of an efficient and user-friendly decision support tool (DST) for determining optimal placement of alternative IRSPs and the trade-off between conflicting objectives in order to cost-effectively manage agricultural water use at the catchment scale. The methodology is tested in the Ali Efenti catchment of the wider Pinios basin in Central Greece, which is the most intensively irrigated region within the country (Loukas et al., 2006). The SWAT model is used as the water balance and crop yield estimator; however, it is not connected to the optimization process, giving its place to a database, which is automatically developed in the form of a look-up table, permitting the assessment of the effectiveness of a large number of different IRSPs across different locations in the catchment within reasonable time. The corresponding problem formulation presented herein is stated as the evaluation of combinations of IRSPs across the catchment which minimize total mean annual irrigation water along with the total crop yield reductions from the baseline. The case study is described in Section 2, while methods and tools are introduced in Section 3, where we present the Decision Support Tool (DST) and its components, the SWAT Ali Efenti model parameterization as well as the optimization structure and problem. Section 4 presents results and finally, Section 5 states the conclusions and discusses on possible ways forward.

\section{CASE-STUDY AND DATA}

The catchment under study (Figure 1) is part of the Pinios river basin in central Greece and flows to Ali Efenti location $\left(2781 \mathrm{~km}^{2}\right)$. An annual rainfall of $993 \mathrm{~mm}$, coupled with high evapotranspiration during summer results to a $40 \mathrm{~m}^{3} \mathrm{~s}^{-1}$ mean annual flow. Elevations in the catchment vary greatly between $74 \mathrm{~m}$ in the large plains of the central and southeast part to $1894 \mathrm{~m}$ in the mountainous landscape in the north-western part (Panagopoulos et al., 2011). Topography was represented by a $50 \times 50 \mathrm{~m}^{2}$ digital elevation model (DEM), while soil information by a geological map (1:50000 scale), provided by the National Institution of Geology and Mineral Exploration (http://www.igme.gr), as the only available map covering entirely the catchment. For representing land cover types, the CORINE Land Cover (CLC) geographical database of 2000 (scale 1:100000) (EEA-ETC/TE, 2002), was used. According to the national data reported to Eurostat (2000) regarding crops allocation at the smaller administrative level, cotton predominated the catchment covering more than $70 \%$ of the arable land (40\% of the total area), which also included alfalfa and corn (irrigated) and winter wheat (nonirrigated). Based on the DEM, the catchment was divided into 97 subbasins (Figure 1), subsequently, the landuse (CLC2000) and the geological (soil) map were overlaid and the dominant landuse and soil types were chosen to be represented in each subbasin. As a result, 97 Hydrologic 
Response Units (HRUs) were created (1 subbasin = $1 \mathrm{HRU}$ ), corresponding to approximately a 30 $\mathrm{km}^{2}$ area on average. From those HRUs, 44 represented cotton (the other crops of the arable land were disregarded), entirely cultivated on alluvial deposits, and 53 forest and pastureland.

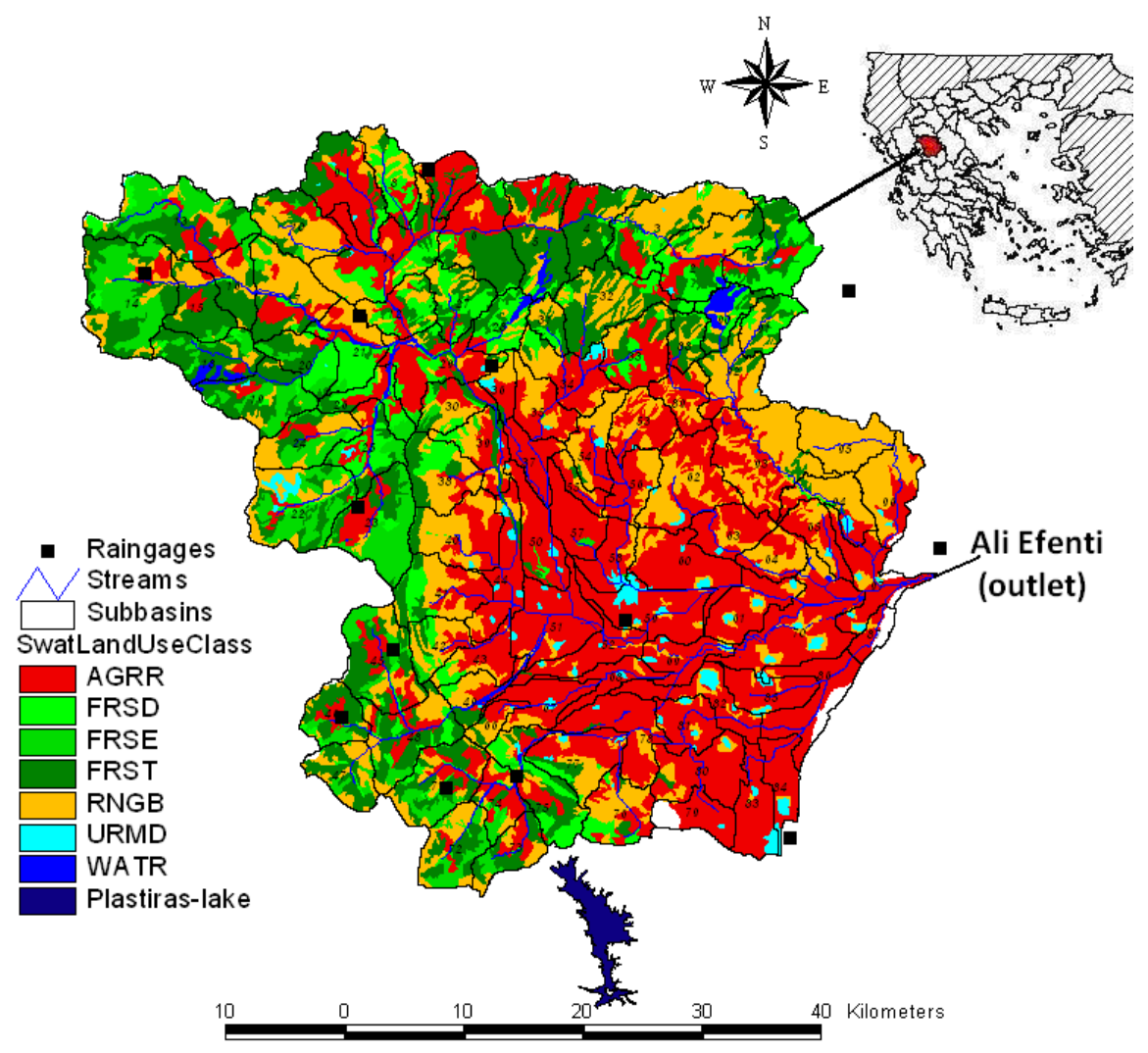

Figure 1. The Ali Efenti catchment

Note: Landcover classes correspond to agricultural land for crops (AGRR), deciduous forest (FRSD), evergreen forest (FRSE), mixed forest (FRST), pasture (RNGB), medium density urban land (URMD) and water areas (WATR). The 'Plastiras' reservoir is located outside the catchment, in the Southern end (bottom of Figure).

\section{METHODS AND TOOLS}

A schematic of the DST is presented in Figure 2. As can be seen, it is comprised of four components: a) the alternative IRSPs, b) the SWAT model, which evaluates their impact on the hydrological response and on the crop yields, after representing the baseline in the catchment, c) an IRSP database that stores irrigation amounts and crop yield reductions from the baseline for all HRUs and IRSPs implemented, as well as, d) a MATLAB-GA, which serves as the optimization engine for the selection and placement of IRSPS in the agricultural land in order to optimize total water use and crop yield objectives.

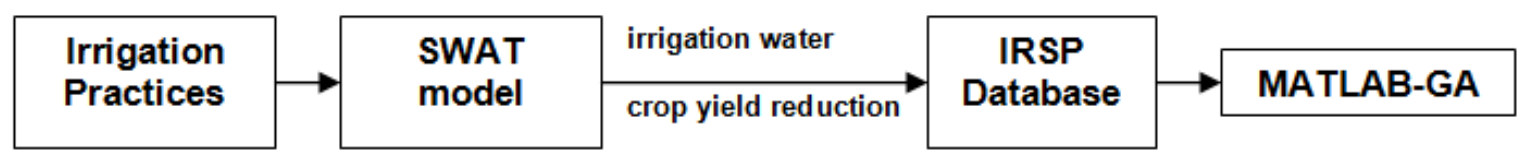

Figure 2. A schematic of the developed Decision Support Tool

\subsection{SWAT model description}

The Soil and Water Assessment Tool (SWAT) is a river basin model developed by the U.S.D.A. Agricultural Research Service (Neitsch et al., 2005). The present study used the SWAT2005 version and AVSWAT-X interface. SWAT divides the catchment into subbasins and subsequently into Hydrologic Response Units (HRUs), which represent the different combinations of land use and soil types in each subbasin. The processes associated with water and sediment movement, crop growth 
and nutrient cycling are linked to management practices and are modelled at the HRU scale. SWAT incorporates a simplified version of the EPIC model (Williams et al., 1995) for crop growth simulation. The curve number approach is used to calculate surface runoff. Remaining water infiltrates into the soil and a storage routing technique simulates water flow through soil layers. If soil water content exceeds field capacity, water can percolate downwards. Actual crop transpiration depends on the soil water content, while the phenomenological development of crops is based on a daily heat unit accumulation, affecting leaf area growth, root depth, biomass and yield. Water stress can limit crop growth according to a daily comparison between actual and potential evapotranspiration. Irrigation schedules (dates and water amounts) are user-defined, while a flexible way is the auto-irrigation routine, triggering irrigation operations within pre-defined thresholds of either plant water stress level or soil water deficit $(\mathrm{mm})$. Finally, SWAT2005 permits water abstraction from 4 different sources: groundwater, the river, a reservoir and an unlimited source of water outside the catchment. The model applies water until soil moisture reaches field capacity, then, it returns the remaining unused water back to the source (Neitsch et al., 2005).

\subsection{Model setup}

The baseline scenario, representing business as usual for the catchment was modeled in SWAT. A typical cotton growth cycle included: a) crop sowing at the end of April, b) $190 \mathrm{~kg}$ of Nitrogen and 35 $\mathrm{kg}$ of Phosphorus fertilization per ha, c) 10 irrigation operations with a $50 \mathrm{~mm}$ dose applied from the end of May until the end of August at a 10-days interval, d) harvest in September with crop yields ranging between 3-4 th ha ${ }^{-1}$ and e) a soil tillage operation in early November. For a big part of the area under study, irrigation water was provided from the Plastiras artificial lake located outside the catchment (Figure 1). In order to accelerate the development and first implementation of our tool described in this study, water was provided from an external unlimited source of water to the whole agricultural land, ignoring possible groundwater abstractions within the catchment. Complete timeseries of measured precipitation and temperature were provided by both the Public Power Corporation (PPC) of Greece and the Hellenic Ministry for the Environment, Physical Planning and Public Works (MEPPPW) for several stations (Figure 1). Annual precipitation ranged from $600 \mathrm{~mm}$ in the eastern part of the catchment to more than $1500 \mathrm{~mm}$ in the most western edge. Observed monthly river flows at the outlet were also provided for a 27-year period (1970-1996) by MEPPPW.

Detailed information on soil properties was not available for the Ali Efenti catchment, thus the three major geological types of flysch, limestones and alluvial were corresponded to an impermeable, a permeable and a semi-permeable soil respectively, based on knowledge on their hydrological behavior. Potential evapotranspiration was calculated with the Penman-Monteith method using historical mean monthly values for meteorological variables. This model setup along with the adjustment of a few soil parameters was found to represent adequately catchment runoff responses. The comparison with the observed monthly flows led to Nash-Sutcliffe coefficients (Nash and Sutcliffe, 1970) above 0.7 for both the calibration and validation periods. Finally, cotton yields were estimated 3.8 tn $^{\text {ha }}{ }^{-1}$ on average, comparable to the actual yields harvested each year. A more detailed description of the Ali Efenti hydrological model parameterization and calibration procedures can be found in the older study of Panagopoulos et al. (2011).

\subsection{Implementation of irrigation schedules}

Seven alternative IRSPs were tested and were differentiated to each other according to the time interval between two irrigation operations and the amount of water applied. A summary of the key information related to the selected IRSPs is presented in Table 1 including the baseline scenario. Three measures (No 2, 3 and 4) apply a deficit irrigation of 20, 30 and $40 \%$ respectively by reducing all irrigation doses proportionally. A fourth measure (No 5) represents rain-fed cultivation of cotton (no-irrigation), while two measures (No 6 and 7) include more frequent irrigation applications. Finally, an auto-irrigation application (No 8), starting at the end of May, was also included, triggering irrigation to fields when the soil water content falls below $100 \mathrm{~mm}$ from field capacity.

\subsection{Development of the database}

The database, developed for use with the DST, stores amounts of irrigation water use and crop yield reduction from the baseline arising from the implementation of each IRSP to all cotton HRUs. It consisted of 2 tables (2 variables) with rows representing the HRUs of the catchment and columns the irrigation water amounts or percentages of yield reduction corresponding to each IRSP. Thus, 
Table 1. List of alternative irrigation scheduling programs selected for the study area

\begin{tabular}{cccc}
\hline $\begin{array}{c}\text { Irrigation } \\
\text { Practice }\end{array}$ & $\begin{array}{c}\text { Number of } \\
\text { irrigation } \\
\text { applications }\end{array}$ & $\begin{array}{c}\text { Maximum } \\
\text { Dose in } \\
\text { SWAT (mm) }\end{array}$ & $\begin{array}{c}\text { Maximum Total } \\
\text { amount } \\
\text { of irrigation water }\end{array}$ \\
\hline 1 (baseline) & 10 & 50 & 500 \\
\hline 2 (20\% deficit) & 10 & 40 & 400 \\
\hline 3 (30\% deficit) & 10 & 35 & 350 \\
\hline 4 (40\% deficit) & 10 & 30 & 300 \\
\hline 5 (rain-fed) & 0 & 0 & 500 \\
\hline 7 (more doses) & 20 & 25 & 300 \\
\hline 8 (auto-irrigation) & 20 & 15 & Automatically \\
\hline
\end{tabular}

each table contained $97 \times 8$ cells, whereby 97 was the number of HRUs in the Ali Efenti catchment and 8 was the number of IRSPs totally tested (Table 1). The procedure for creating the database was simple and completely automated. A set of scripts in MATLAB found and opened the input 'mgt' files used by SWAT to identify practices within each HRU. It recognized land use information and set the values which were required to represent each practice. For example, in order to assess the $30 \%$ deficit irrigation in cotton HRUs, the script related to IRSP no. 3 in Table 1 was executed, recognized all 'mgt' files with cotton as their land use type and set the irrigation dose at $35 \mathrm{~mm}$ instead of 50 $\mathrm{mm}$. SWAT was then run for 5 years (2000-2004) thus simulating mean annual values that would have been produced from all HRUs during this period, if an IRSP was applied. From the consecutive runs of all 8 IRSPS, the mean annual results from each HRU were obtained, populating the database. Its contents were then used in the optimization process in the form of a look-up table, instead of running SWAT again to evaluate each alternative irrigation practice.

\subsection{The MATLAB genetic algorithm and multi-objective optimization}

For multi-objective optimization, where the solution is a multi-dimensional front (the pareto front), GAs have been developed to converge to the optimal front and ensure the conservation of an adequate spread of solutions on that front. One of the most popular, robust, efficient and fast multiobjective GAs is the Non-dominated Sorted Genetic Algorithm (NSGA-II) (Deb et al., 2002). In this work, a controlled, elitist GA, that is a variant of NSGA-II, as coded in the MATLAB R2007b GA toolbox, was used to drive the optimization process. The controlled elitism works in favor of individuals with a better fitness value (rank). As the algorithm progresses, it maintains population diversity for convergence to an optimal Pareto front by using the options 'ParetoFraction' and 'DistanceFunction'. The first limits the number of individuals on the Pareto front (elite members), and the second is an embedded crowding distance function that helps to maintain their diversity by favouring individuals that are relatively far from each other. A random or user-defined initial population is generated, and continues with the generation of a sequence of new populations by performing individual ranking, selection, crossover and mutation according to several available options in the toolbox (this selection is a heuristic problem based on trial and error) (MATLAB, 2010).

The optimization process for the Ali Efenti catchment started with the initialization of a population. Each individual consisted of genes equal to the number of decision variables (the number of HRUs). The values of genes of an individual form the genotype, while their real representation (phenotype) corresponds to a combination of IRSPs in the HRUs of the catchment. A real integer coding was selected to represent this problem, thus the genes of each individual were expressed by integer values between 1 and 8 , the 8 alternative situations as they were numbered in Table 1 . For the 53 non-agricultural HRUs the GA was constrained to choose values only from the 1st column so that it would not delay by selecting between 'zeros' of irrigation water and yield reductions stored in all the 8 columns of the database. The representation of one hypothetical individual (chromosome), corresponding to a complete, composite solution for the entire catchment, is shown in Figure 3. 


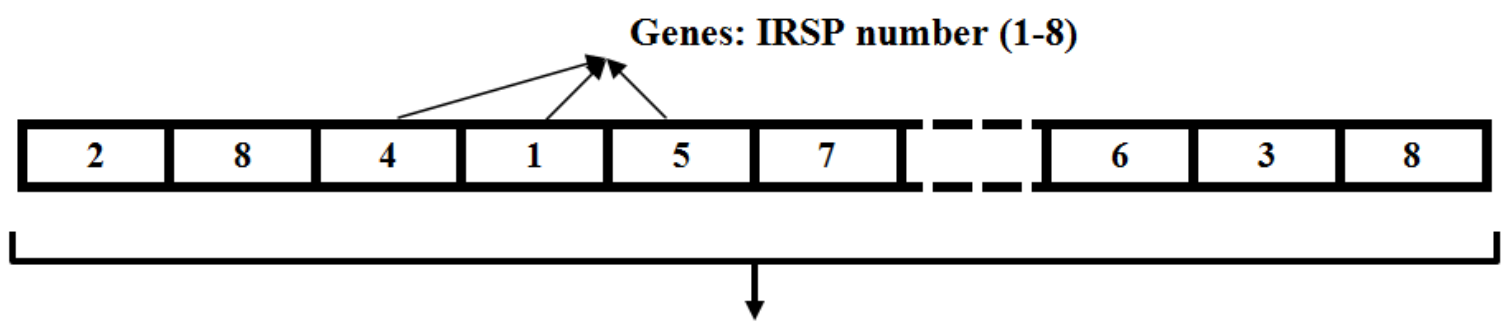

Chromosome (length: number of HRUs - 97)

Figure 3. A chromosome representing a complete IRSP scheme in the Ali Efenti catchment (a composite management solution for the entire catchment)

The algorithm then created a sequence of new populations by performing individual ranking, tournament selection, scattered crossover with a probability of 0.8 and Gaussian mutation (MATLAB, 2010). A population of 150 with a total maximum number of generations equal to 10000 was selected for the specific problem of the two-criterion optimization. A Pareto fraction equal to 0.4 , limited the number of solutions in the first Pareto front to 60 . After conducting a detailed sensitivity analysis of the MATLAB-GA parameter sets, these specific options were found to represent the most appropriate GA parameters to guarantee the convergence to the optimal front within reasonable time. The objectives for optimization (minimization here) were: a) the total mean annual irrigation water applied in the catchment estimated in $\mathrm{mm}$ over the total irrigated land - Irr water and b) the mean annual reduction of the cotton yield in the catchment compared to the baseline expressed in tn ha ${ }^{-1}$ of the arable land - Cyld red:

$\min \left[\sum_{i=1}^{97} \operatorname{Irr}_{\text {water }}(i, j) \wedge \sum_{i=1}^{97}\right.$ Cyld $\left._{\text {red }}(i, j)\right]$

where $i, j$ was the element of the matrix, which corresponded to $I r r_{\text {water }}$ spent or Cyld ${ }_{\text {red }}$ caused in the $i_{\text {th }}$ HRU when the $j_{\text {th }}$ IRSP was implemented $\left(i_{\max }=97, j_{\max }=8\right)$.

\section{RESULTS AND DISCUSSION}

Under conventional irrigation practices, water used and cotton yield produced in the Ali Efenti catchment were $462 \mathrm{~mm} \mathrm{y}^{-1}$ and $3.8 \mathrm{tn} \mathrm{ha}^{-1}$ respectively. However, when less water was provided, more water stress days were simulated by SWAT, thus, smaller crop yields were calculated. The optimal trade-off frontier of $I r r_{\text {water }}$ - Cyld ${ }_{\text {red }}$ produced is demonstrated in Figure 3 along with a catchment management scheme, corresponding to a Pareto solution of $400 \mathrm{~mm}$ water used, which caused a yield reduction of 0.2 tn $\mathrm{ha}^{-1} \mathrm{y}^{-1}$.

The trade-off schemes produced on the optimal Pareto front of Figure 4 provided information on 60 different IRSP combinations, which resulted in various total water use and crop yield reductions from the baseline. A first attempt was to discover optimal solutions that considerably reduced water use but which did not impact significantly on yields. Such a compromise was the solution represented by a red triangle on the front of Figure 4. By spending 13\% less water on an annual basis (400 instead of $462 \mathrm{~mm})$, a small deviation of $4.6 \%$ from the produced yields of the baseline was observed $(0.2 \mathrm{tn}$ $\mathrm{ha}^{-1}$ reduction). This management scheme depicted on the map of the catchment (Figure 4) proposed a deficit irrigation in the most southwestern part of the catchment (measures 2, 3 and 4), along with an auto-irrigation scheduling in the southeastern part (measure 8) and a more frequent irrigation scheduling in the North (measure 6). Indeed, high precipitation in the west was responsible for a significant effective rainfall, even during the cotton growth cycle (for the given physical catchment characteristics), which lead the algorithm to reduce irrigation water in these areas without significant yield reduction, following a rational approach to reach the compromise solution analyzed. On the other hand, auto-irrigation was mostly selected in the eastern part. When applying such a practice, the optimization model opted to apply almost the same water to fields of this low-rainfall area compared to the baseline; however, by providing water according to a soil deficit criterion, fewer water stress days were simulated and crop yields were somehow greater. The soil deficit threshold selected $(100 \mathrm{~mm})$ implied that cotton could uptake water from larger depths (even when soil moisture falls nearly $100 \mathrm{~mm}$ below field capacity), thus irrigation could be applied less 
frequently and in this case for example, in $4-5$ doses of $100 \mathrm{~mm}$, instead of 10 or more doses of less water. Additionally, in the baseline, a smaller amount of irrigation water $(462 \mathrm{~mm})$ compared with the one defined in the management operation files $(500 \mathrm{~mm})$ was applied by SWAT during the cotton

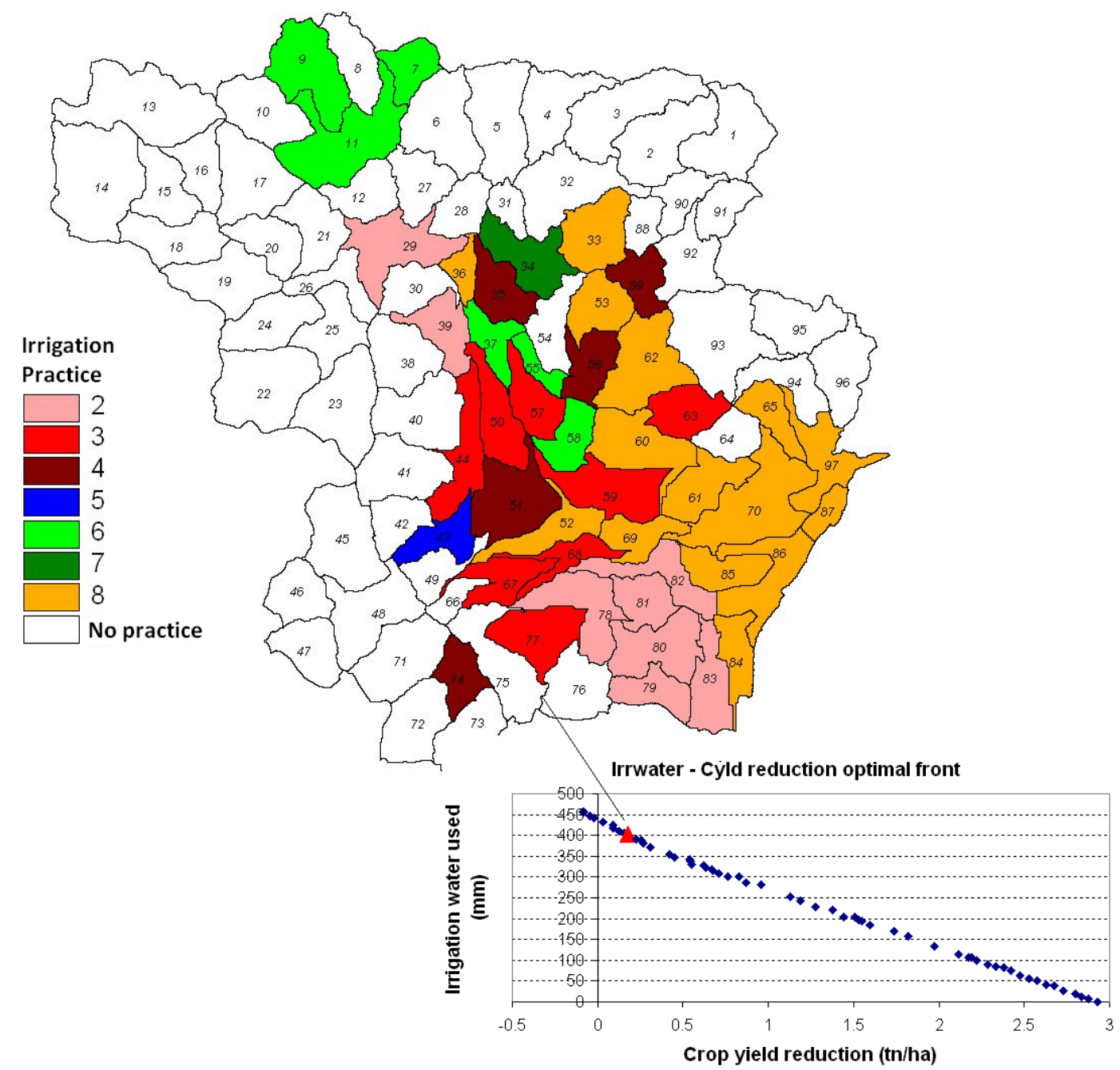

Figure 4. A management solution selected from the optimal trade-off frontier produced and its depiction on the Ali Efenti catchment map. The irrigation practices 2-8 correspond to Table 1, while non-agricultural HRUs (subbasins) are depicted with no-colour areas

growth cycle. This happened because in some of the operation dates soil water content was reaching field capacity with less than the user-defined dose of $50 \mathrm{~mm}$. Hence, the remaining water $(500-462=38 \mathrm{~mm})$ was returned back to the source. In this way, soil was filled with water to field capacity frequently, thus, surface runoff, lateral flow and percolation increased, reducing the overall crop water use efficiency. In contrast, precise or auto-irrigation was found to lead to better water exploitation from the cultivation, increasing, although slightly $\left(\sim 0.1 \mathrm{tn} \mathrm{ha}^{-1}\right.$ or $\left.3 \%\right)$, crop yields. In the North, the algorithm chose to apply an irrigation schedule with double operations but with the half water amount compared to the baseline. This is possibly attributed to the local topographical features. As slopes are high there, the model enhanced lateral subsurface flow with quick soil water content reduction. Therefore, a more frequent irrigation schedule with reduced doses was needed in order to avoid soil water fulfilment and thus high lateral flow losses, leading to a few water stress days that retain cotton yields close to the baseline levels.

Other important solutions on the Pareto front were those concentrated close to the $y$ axis, thus those which resulted in zero yield reductions or even small yield increases with a small water saving. As demonstrated, there were plenty of management schemes that could reduce irrigation water abstractions by $20 \mathrm{~mm} \mathrm{y}^{-1}$ or $4-5 \%$ with a potential $1-2 \%$ yield increase. These measures possibly did not include the deficit irrigation measures (2-4). On the other hand, rain-fed agriculture in the study area lead to a drastic decrease of crop yields by approximately 3 tn ha $^{-1} \mathrm{y}^{-1}$ or $75 \%$ from the 
baseline, indicating that such an agricultural strategy is not cost-effective in this highly waterdemanding area. Another important point in this analysis is related to the possible socio-economic limitations arising when the objectives are aggregated at the total catchment area. For instance, by analyzing the first (compromise) solution it is obvious that water saving is mostly achieved in areas where crop yield reductions also occur, while in other parts of the catchment, which correspond to other agricultural communities, farmers' income is not highly disturbed. Even in this case however, the analysis provides the opportunity to take such local constraints into consideration by analyzing neighbor solutions from the Pareto front, which result to similar overall targets but which may differ in the corresponding allocation schemes.

Overall, the database improved the efficiency of the optimization procedure. The total time needed for the termination of the optimization process was $1 \mathrm{~h}$ on an Intel(R) Core(TM)2 CPU@ $2.13 \mathrm{GHz}$ and 4 GB RAM, thus the algorithm spent only 0.002 sec/evaluation $(150 \times 10000$ evaluations) instead of 10 sec/evaluation that would have been needed if there had been a dynamic link to SWAT.

\section{CONCLUSIONS AND FUTURE RESEARCH}

The decision support tool presented in this paper significantly accelerated the optimization process by including an irrigation water and crop yield estimator look-up table, populated by the SWAT model after testing different irrigation scheduling programs in the catchment. An acceptable compromise of irrigation water management in the Ali Efenti catchment included: 1) the application of a deficit irrigation program in the western part of the catchment, where effective rainfall was significant, 2) a more precise program in the southeast part of the catchment based on an auto-irrigation scheduling program, and 3) a more frequent irrigation operation program with lower doses in the northern part of the catchment. This combined agricultural water management solution led to a total water depth saving of approximately $60 \mathrm{~mm}\left(600 \mathrm{~m}^{3} \mathrm{ha}^{-1}\right)$ or a difference of $13.5 \%$ from the baseline by reducing annual cotton harvest yields by less than $5 \%$. The multi-objective optimization method addressed the importance of analyzing solutions that reflect the reduction of more than one objective at the same time. This can assist the decision-making process by supporting the analysis of the impact of multiple spatial patterns of irrigation programs within the area providing the opportunity to impose additional local constraints. Further improvements of the conceptual design of our tool are currently in progress including the testing of more kinds of agricultural practices such as waste water reuse and improvement of the irrigation canals' conveyance efficiency. Additionally, great efforts are currently under way to translate the economic indicator to the total cost of practices implementation including direct cost estimates of yield reduction and the capital and maintenance cost of those practices, whose operation relies on the appropriate constructions and/or equipment. As far as the software aspect is concerned, significant improvements in the optimization scheme are expected from the linkage of the database with more robust and efficient evolutionary algorithms able to further reduce the duration of the optimization process. This will make the tool even more adaptable in very large areas such as the whole Pinios river basin of Thessaly with an area of $10500 \mathrm{~km}^{2}$ divided in hundreds HRUs. Even in this version however, it is suggested that the tool offers great opportunities for experimentation with scenarios for saving water in agriculture, assisting in a costeffective water resources management at the catchment scale.

\section{ACKNOWLEDGEMENTS}

The current research was conducted under the project 'i-adapt', which is one of the Pilot projects on Development of Prevention Activities to Halt Desertification in Europe, partly funded by DG Environment of the European Commission. http://i-adapt.gr/.

\section{REFERENCES}

Allen R.G., Pereira L.S., Raes D. and Smith M. (1998). Crop evapotranspiration. Guidelines for computing crop water requirements, FAO Irrigation and Drainage Paper, 56, Rome.

Arabi M., Govindaraju R.S., Hantush M.M. (2006). Cost-effective allocation of watershed management practices using a genetic algorithm, Water Resources Research, 42, W10429, DOI:10.1029/2006WR004931. 
Arnold J.G., Srinivasan R., Muttiah R.S. and Williams.J.R. (1998). Large area hydrologic modeling and assessment part I: model development, Journal of the American Water Resources Association, 34(1), 73-89.

Deb K., Pratap A., Agarwal S. and Meyarivan S. (2002). A fast and elitist multiobjective genetic algorithm: NSGA-II, IEEE Transactions of Evolutionary Computation, 6(2), 182-197.

Directive 2000/60/EC of the European Parliament and of the council of 23 October 2000 establishing a framework for Community action in the field of water policy, Official Journal of the European Communities, L327/1.

EEA-ETC/TE (2002). CORINE Land Cover update. I\&CLC 2000 project, Technical Guidelines. URL: http://etc-lusi.eionet.europa.eul. Accessed in June 2010.

Eurostat (2000). URL: http://epp.eurostat.ec.europa.eu. Accessed in June 2010.

Feng $\mathrm{H}$. and Baoguo L. (2010). Assessing grain crop water productivity of China using a hydro-modelcoupled-statistics approach Part I: Method development and validation. Agricultural Water Management, 97(7), 1077-1092.

Gassman P.W., Reyes M.R., Green C.H. and Arnold J.G. (2007). The Soil and Water Assessment Tool: Historical Development, Applications, and Future Research Directions, Transactions of the ASABE, 50(4), 1211-1250.

Jha M., Rabotyagov S. and Gassman P.W. (2009). Optimal placement of conservation practices using genetic algorithm with swat, International Agricultural Engineering Journal, 18(1-2), 41-50.

Loukas A., Mylopoulos N. and Vasiliades L. (2006). A Modeling System for the Evaluation of Water Resources Management Strategies in Thessaly, Greece, Water Resources Management, 21,16731702.

Luo Y., He C., Sophocleous M. and Yin Z. (2008). Assessment of crop growth and soil water modules in SWAT2000 using extensive field experiment data in an irrigation district of the Yellow River Basin, Journal of Hydrology, 352(1-2), 139-156.

Makropoulos C. and Butler D. (2005). A multi-objective evolutionary programming approach to the "object location" spatial analysis and optimisation problem within the urban water management domain, Civil and Environmental Systems, 22(2), 85-107.

MATLAB (2010). Global Optimization Toolbox, User's Guide. URL: http://www.mathworks.com/access/helpdesk/help/pdf doc/gads/gads tb.pdf

Nash J.E. and Sutcliffe J.V. (1970), River flow forecasting through conceptual models, Journal of Hydrology, 10, 282-290.

Neitsch S.L., Arnold J.G., Kiniry J.R. and Williams J.R. (2005). Soil and water assessment tool-theoretical documentation-version 2005. Blackland Research Center - Agricultural Research Service, Texas USA.

Nicklow J., Reed P., Savic D., Dessalegne T., Harrell L., Chan-Hilton A., Karamouz M., Minsker B., Ostfeld A., Singh A. and Zechman E. (2010). State of the Art for Genetic Algorithms and Beyond in Water Resources Planning and Management, Journal of Water Resources Planning and Management, 136(4), 412-432.

Panagopoulos Y., Makropoulos C. and Mimikou M. (2011). Diffuse surface water pollution: Driving factors for different geoclimatic regions, Water Resources Management, 25(14), 3635-3660.

Panagopoulos Y., Makropoulos C. and Mimikou M. (2012). Decision support for diffuse pollution management, Environmental Modelling \& Software, 30, 57-70.

Rabotyagov S., Campbell T., Jha M., Gassman P., Arnold, J., Kurkalova L., Secchi Z., Feng H. and Kling C.L. (2010). Least-cost control of agricultural nutrient contributions to the Gulf of Mexico hypoxic zone, Ecological Applications, 20(6), 1542-1555.

Schwefel H.P., 2000. Advantages (and disadvantages) of evolutionary computation over other approaches. In: Back, T., Fogel, D.B., Michalewicz, Z., (eds.), Evolutionary computation 1, Basic algorithms and operators. Institute of Physics, Philadelphia.

Srivastava P., Gupta A.K. and Kalin L. (2010). An Ecologically-Sustainable Surface Water Withdrawal Framework for Cropland Irrigation: A Case Study in Alabama, Environmental Management, 46(2), 302-313.

Tan K.C. Lee T.H. and Khor E.F. (2002). Evolutionary Algorithms for Multi-Objective Optimisation: Performance Assessments and Comparisons, Artificial Intelligence Review, 17(4), 253-290.

Williams J.R. (1995). The EPIC model. In: Singh, V.P. (ed.). Computer models of watershed hydrology. 909-1000. Water Resources Publications. Highland Ranch, Co, USA.

Wriedt G., Van der Velde M., Aloe A. and Bouraoui F. (2009). Estimating irrigation water requirements in Europe, Journal of Hydrology, 373, 527-544. 